\title{
TWO-DIMENSIONAL GRAIN GROWTH IN ICE
}

\author{
By D. v.D. S. Roos \\ (National Physical Research Laboratory, C.S.I.R., Pretoria, South Africa)
}

\begin{abstract}
The rate of grain growth in thin sections of polycrystalline ice was found to be practically the same at temperatures between $0^{\circ} \mathrm{C}$. and $-1{ }^{\circ} \mathrm{C}$. and not to depend to a great extent upon initial average grain size. In general, several hundred hours of annealing at $0^{\circ} \mathrm{C}$. reduced the number of grains by a factor of about 3 . The growth rate of certain grains was much greater than the average and these increased about a hundredfold in area. The rate of change of the average diameter was approximately inversely proportional to the annealing time. Grain boundary angles tended to average $120^{\circ}$ irrespective of the number of sides per grain. Both grain shapes and crystallographic orientations were found to influence boundary migration rates. After long periods of annealing there was a strong tendency for the surviving grains to have their $c$-axes oriented parallel to the plane of the ice surface.
\end{abstract}

RÉsumÉ. Croissance bidimensionelle du cristal dans la glace. On a constaté que la vitesse de croissance des grains dans des lames minces de glace polycristalline est sensiblement la même à des températures entre $0^{\circ}$ et $-\mathrm{I}^{\circ} \mathrm{C}$, et qu'elle n'est guère influencée par la grandeur moyenne initiale des grains. Généralement, après quelques centaines d'heures à $0^{\circ} \mathrm{C}$, le nombre des grains diminue d'un facteur 3 . Certains grains augmentent avec une vitesse supérieure à la moyenne en augmentant la surface au centuple. La vitesse de variation du diamètre moyen varie en raison inverse du temps. Les angles entre les limites des grains s'approchent en moyenne de $120^{\circ}$, indépendamment du nombre des côtés de chaque grain. La forme des grains ainsi que leur orientation cristallographique influencent la migration des limites. Les grains qui subsistent après des longues périodes ont une tendance prononcée d'orienter leurs axes $c$ parallèlement à la surface de la glace.

Zusammenfassung. Zweidimensionales Kornwachstum in Eis. Die Kornwachstumsgeschwindigkeit in Dünnschliffen aus polykristallinem Eis stellte sich als temperaturunabhängig im Bereich von o bis $-1^{\circ} \mathrm{C}$ heraus und war kaum abhängig von der anfänglichen durchschnittlichen Korngrösse. Allgemein verringerte sich die Kornzahl nach mehreren hundert Stunden bei $0^{\circ} \mathrm{C}$ ungefähr um den Faktor drei. Bestimmte Körner wuchsen aussergewöhnlich schnell und ihre Fläche vergrösserte sich auf das etwa hundertfache. Die Änderung des durchschnittlichen Korndurchmessers war annähernd umgekehrt proportional zur Zeit. Die von Korngrenzen eingeschlossenen Winkel strebten dem Wert von $120^{\circ} \mathrm{zu}$, ohne Rücksicht auf die Anzahl der Kornseiten. Sowohl Korngestalt als auch kristallographische Orientierung beeinflussen die Wanderungsgeschwindigkeit der Korngrenzen. Nach langer Zeit neigten alle noch vorhandenen Körner stark dazu, ihre $c$-Achsen parallel zur Eisoberfläche zu orientieren.

\section{Introduction}

Grain growth in ice was first investigated in this laboratory in order to establish whether or not the crystal structure of a hailstone would alter in the interval between the time of its formation and the time of its structural examination (Carte, I96I). It was concluded that the changes which could occur within minutes when the temperature was close to the melting point would be insignificant, but that appreciable changes could take place within hours. Further quantitative results for specimens of polycrystalline ice are presented in this paper. Annealing times have been extended up to $900 \mathrm{hr}$. at $\mathrm{o}^{\circ} \mathrm{C}$.

\section{Procedure}

Most of the specimens that were investigated were thin slices $(<\mathrm{Imm}$. thickness) cut through the centres of hailstones larger than $3 \mathrm{~cm}$. in diameter. A few thin sections of polycrystalline ice were prepared in the laboratory by freezing a film of water by intense cooling at the centre, thereby producing radially oriented crystals. Some specimens were provided with reference axes by embedding crosswires within them.

The specimens were sealed inside a small glass bottle and kept at a temperature of $0^{\circ} \mathrm{C}$. in an ice-water mixture. Continual repacking of the ice bath enabled this temperature to be maintained for hundreds of hours. Lower temperatures were maintained to an accuracy of $\pm 0 \cdot I^{\circ} \mathrm{C}$. in a petropine bath. Short-term annealing was performed by immersing the specimens, sealed between glass plates, directly into the cold liquid to ensure good thermal contact. 
After an annealing period, the specimens were temporarily transferred to an environment at about $-12^{\circ} \mathrm{C}$. where they were photographed between crossed polaroids and in ordinary transmitted light. Individual grains showed up best in colour photographs.

\section{Grain Growth as a Function of Temperature and Time}

(a) Temperatures between $o^{\circ}$ and $-I^{\circ} \mathrm{C}$.

The dependence of grain growth in ice on temperature was treated by Rigsby (1963) and Carte (I96I). It was found that the growth rate decreased rapidly with temperature. Further experiments have been carried out to establish whether or not the rate is very sharply dependent on temperature near to the melting point. This was undertaken in order to ascertain the accuracy with which it would be necessary to control the temperature for longterm annealing in the vicinity of the melting point.

Annealing times up to $\mathrm{I} 5 \mathrm{hr}$. were used. The number of grains per unit area was determined after various times. Hence the average crystal areas and diameters were obtained and then related to annealing time. The average diameter was taken as the equivalent circular diameter of the average grain.

The results for nine specimens covering a wide range of average initial grain diameters $\left(0.3\right.$ to $\mathrm{I} \cdot 6 \mathrm{~mm}$.) and four different temperatures $\left(-0 . \mathrm{I},-0.2,-0.5\right.$, and $-\mathrm{I} \cdot \mathrm{O}^{\circ} \mathrm{C}$. $)$ are shown in Figure I. Observational areas were so selected in all specimens as to contain about 280 grains initially. This number decreased to about $\mathrm{I}$ io after $15 \mathrm{hr}$. of annealing time.

It will be seen that every specimen gave results that conformed closely to the relation which applies for certain stages of grain growth in metals (Burke and Turnbull, r952), viz.:

$$
D=k t^{n}
$$

where $D$ is the average grain diameter, $t$ is the annealing time, $k$ is a constant, and $n$ is constant for a given temperature. As shown in Figure I, values for $n$ ranged between $0 \cdot I_{1}$ and $0 \cdot 23$. There is no obvious correlation between $n$ and either temperature or average initial grain size. Thus it may be concluded that, at least over this restricted range of temperature, grain growth depends less on temperature or average grain size than on other factors. One factor not taken into account, for example, is size distribution of the grains.

\section{(b) Short-period annealing}

Since crystal structure alters most rapidly in the early stages of annealing further studies were made of specimens annealed for short periods only. Six specimens (identified by the letters a to f) were prepared from hailstones that differed significantly in structure from one another. They were kept at $-\mathrm{O} \cdot \mathrm{I}^{\circ} \mathrm{C}$. for $3 \mathrm{hr}$. during which time they were photographed eight times. Most specimens had several regions that differed significantly in grain size. Regions of small (about $0.5 \mathrm{~mm}$.), medium ( $\mathrm{I} \mathrm{mm}$.) and large ( $1.5 \mathrm{~mm}$.) grains were selected such that each area included $\mathrm{I} 75,80$ and 60 initial grains respectively.

Results are indicated in Figure 2. Again, $\log D$ is nearly proportional to $\log t$ and slopes show no obvious relationship to average grain size. Average values of $n$ from Figure 2 for initially small, medium and large grains are $0.03,0.07$ and 0.04 . All these values are significantly lower than those obtained for the results for annealing periods up to $\mathrm{I} 6 \mathrm{hr}$., shown in Figure $I$.

Differentiation of equation ( $\mathrm{I}$ ) and substitution of $n=0.04$ (the arithmetic mean of all results in Figure 2) gives:

$$
\frac{d D}{d t} \propto \frac{\mathrm{I}}{t^{\mathrm{I}-n}}=\frac{\mathrm{I}}{t^{0.96}} \approx \frac{\mathrm{I}}{t}
$$

i.e. the rate of grain growth in the earliest stages is almost exactly inversely proportional to annealing time. 


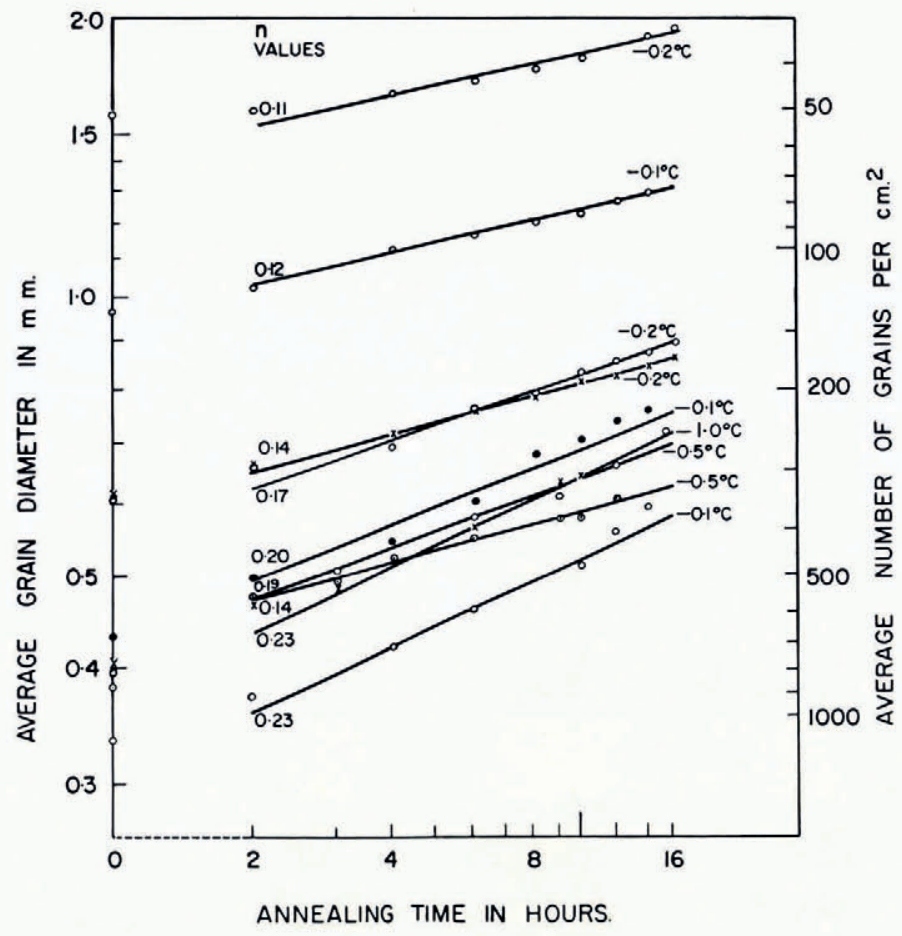

Fig. I. Average grain size versus annealing time for nine specimens at temperalures of $-0 \cdot I,-0 \cdot 2,-0 \cdot 5$, and $-I \cdot 0^{\circ} \mathrm{C}$. $n$ is the exponent in the relation $D=k t^{n}$ where $D$ is average grain diameter and $t$ is time

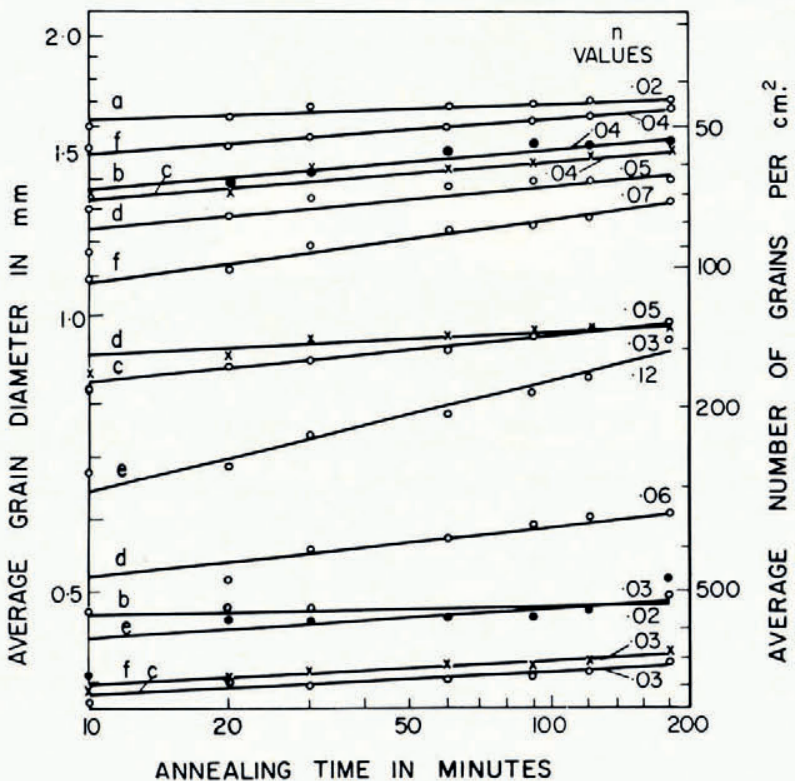

Fig. 2. Average grain size versus annealing time for six specimens annealed for $3 \mathrm{hr}$. at $\mathrm{o}^{\circ} \mathrm{C}$. $n$ has the same meaning as in Figure I 
(c) Long-period annealing

Annealing periods were extended to hundreds of hours at $0^{\circ} \mathrm{C}$. in the next series of experiments. Photographs of three specimens before and after annealing are shown in Figure 3 . Specimens A and B remained at $0^{\circ} \mathrm{C}$. for $600 \mathrm{hr}$. and c for $400 \mathrm{hr}$. and they were all cut from large hailstones.
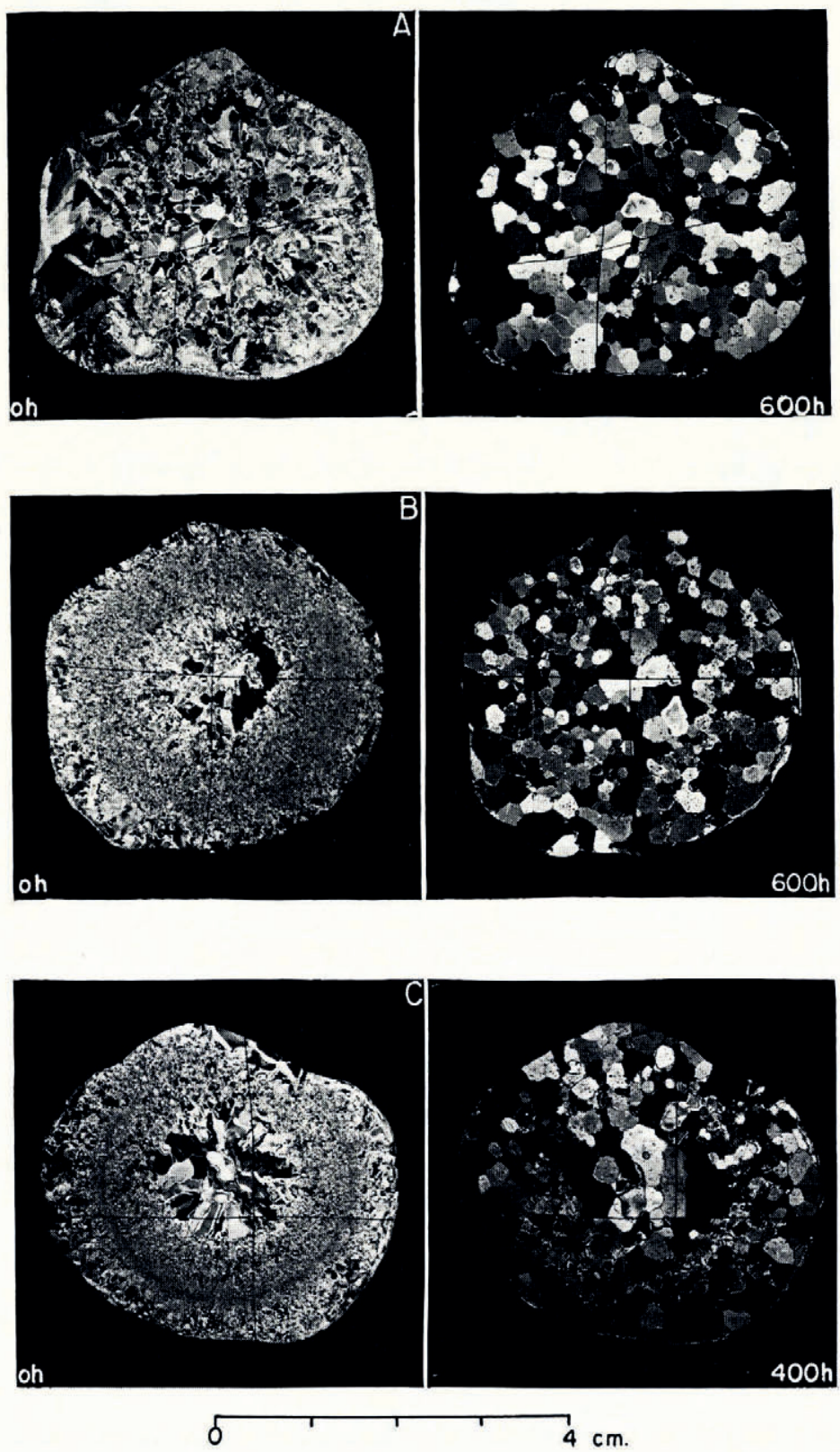

Fig. 3. Grain structures of specimens $\mathrm{A}, \mathrm{B}$ and $\mathrm{c}$ between crossed polaroids before (left-hand column) and after (right-hand column) long term annealing at $o^{\circ} \mathrm{C}$. for the periods indicated 
Results for A, B and $\mathrm{c}$ are given in Figure 4. As in Section 3 (b), observations on every specimen were made on three areas each having different sizes of grains.

It will be noted that the general trend with time for specimens A and B was towards a more uniform size of grains, although the medium-size grains of specimen в actually became, on the average, slightly bigger than those initially the largest ones. The three curves for specimen c remained nearly parallel, indicating that even after $400 \mathrm{hr}$. the zones initially composed of grains of different sizes were still distinguishable.

The curves of Figure 4 show that equation (I) does not apply for extended periods of time. Also, they corroborate the trend of decreasing slope with time which is apparent from Section 3 (b). For example, the average slopes (values of $n$ ) for all curves in Figure 4 are 0.05 at $5 \mathrm{hr}$.; $\mathrm{o} \cdot \mathrm{I} 2$ at $50 \mathrm{hr}$; ; and 0.14 at $300 \mathrm{hr}$.

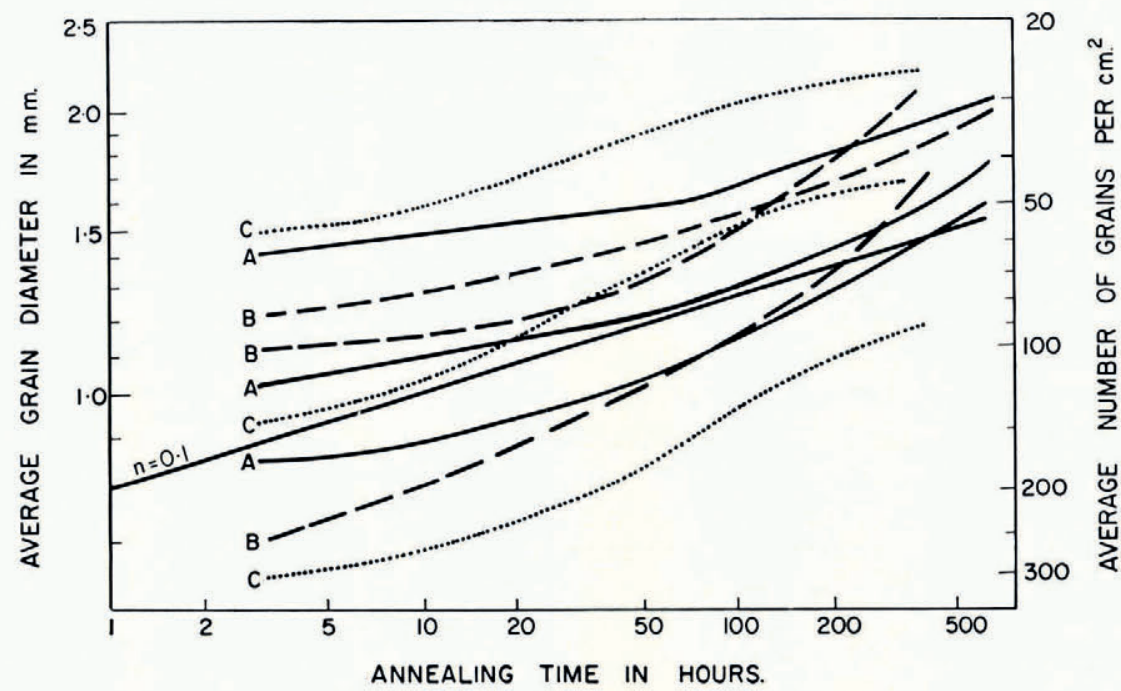

Fig. 4. Average grain sizes of specimens $\mathrm{A}, \mathrm{B}$ and $\mathrm{c}$ (shown in Figure 3$)$ versus annealing time at $0^{\circ}$ C. for a maximum period of 25 days. The straight line having $n=0 \cdot I$ represents the relation $D=k t^{0.1}$ where $D$ is the average grain diameter and $t$ is time

A straight line of slope $n=0 \cdot \mathrm{I}$ has been drawn in Figure 4 . It will be seen that such a slope gives at least an order-of-magnitude estimate of how grain size changes with time up to hundreds of hours at $0^{\circ} \mathrm{C}$. (Extrapolation of such a line indicates that a tenfold increase in average diameter would take place in about a million years. Such extrapolation is not justified by the present results.)

It is noteworthy that zones of initially small grains, despite having numerous air bubbles, did not necessarily exhibit lower growth rates than the other zones. In fact the average growth rate at $300 \mathrm{hr}$. was greater for the small grains than for the others.

Figure 5 shows an artificially made specimen before and after $400 \mathrm{hr}$. of annealing. A few of the tiny grains in the centre increased hundreds of times in area at the expense of their minute neighbours. The thin radial crystals increased in width and often became shorter but, in spite of the long annealing time, did not lose their radial orientation.

The difference in behaviour of the average grain in two zones of grains with the same average size can be ascribed to a few individual grains that greatly influenced the average behaviour. Characteristics of individual grains were therefore examined and are given in the following section. 

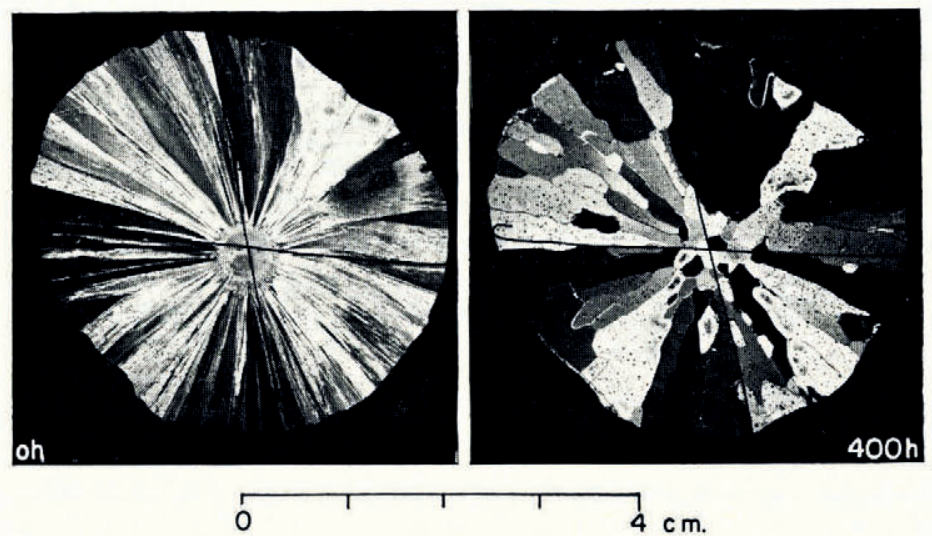

Fig. 5. Artificially made specimen showing radial crystals between crossed polaroids before (left) and after (right) $400 \mathrm{hr}$. of annealing at $o^{\circ} \mathrm{C}$.

\section{Grain Shapes}

It is well known from earlier studies of grain growth in both metals and non-metals that boundary movements may depend on grain shapes. In fact Tamman and Dreyer (I929) concluded that shape is the controlling factor for grain growth in ice. Geometrical parameters that were investigated in order to test this conclusion were the number of sides per grain, angles between grain boundaries and curvature of the boundaries. Figure 6 shows the distribution of number of sides per grain in a specimen after $900 \mathrm{hr}$. of annealing at $0^{\circ} \mathrm{C}$. The average and the modal number of sides per grain was six. However, it will be noted that the distribution is broad with grains ranging from triangular to nine-sided. Annealing had the general effect of broadening the distribution in the direction of grains having more sides. A similar broadening of the size-distribution curve also occurred. Even after several hundred hours of annealing some of the smaller grains survived, virtually unaffected in size. Practically all grains smaller than average had six or fewer sides while those larger than average had more than six sides.

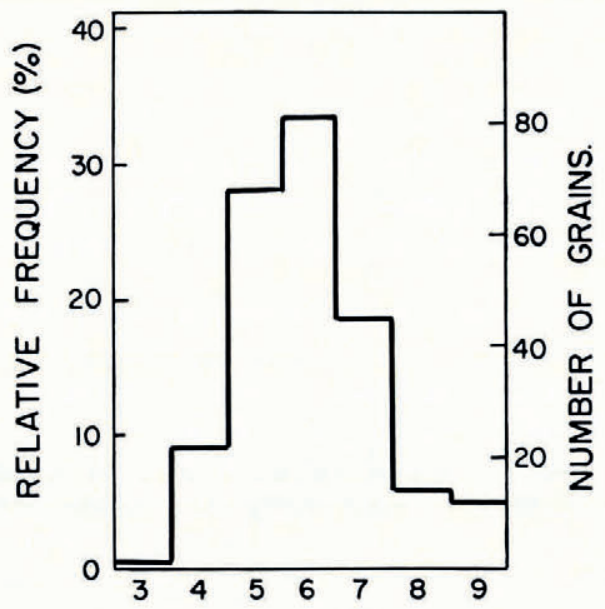

NUMBER OF SIDES PER GRAIN.

Fig. 6. Distribution of number of sides per grain in a specimen annealed for goo hr. at $o^{\circ} \mathrm{C}$. 
Grains which rapidly consume slower-growing or static neighbours and thereby develop the longest perimeters, will obviously tend to have the most neighbours, i.e. the most sides. This state of affairs need not persist, for a growing grain may first consume surrounding (smaller) grains and then encounter other grains that have grown as rapidly as itself. Its number of sides will then decrease after the initial increase. Such cases were observed.

The expectation was that all grain boundary angles would tend to $120^{\circ}$ as the equilibrium state was reached, as for single phase metals (Burke and Turnbull, i952). To see whether or not this happened, angles were measured on the photographs of the specimens between crossed polaroids. Later, the angles were measured on a formvar replica of the ice surface after sufficient thermal etching had revealed the grain boundaries. The latter method proved to be the best because of the excellent definition of the boundaries.

It was found that even after $600 \mathrm{hr}$. of annealing, angles of exactly 120 degrees were rare. For example, fifteen tri-crystal joints (comprising 45 angles) selected on the basis of the angles all appearing to be fairly close to I 20 degrees, gave the following distribution:

$\begin{array}{cc}\text { Deviation from } 120 \text { degrees } & \text { Percentage of angles } \\ 0-5^{\circ} & 40 \\ 6-10^{\circ} & 27 \\ \mathrm{I}-15^{\circ} & \mathrm{I} 5 \\ \mathrm{I} 6-20^{\circ} & 5 \\ 2 \mathrm{I}-25^{\circ} & \mathrm{I} 3\end{array}$

The arithmetic mean value of the grain boundary angle in this specimen was $120^{\circ}$, with angles (hereafter called equilibrium angles) ranging from $60^{\circ}$ to nearly $180^{\circ}$. Figure 7 shows six of the equilibrium angles belonging to four different grains. The equilibrium angles of I 50 grains having five, six or seven sides were measured in order to establish whether angles were related to number of grain sides. The average interior angles of a pentagon, a hexagon and a heptagon are 108, 120 and 128.6 degrees respectively, while the corresponding equilibrium angles averaged I I 9 , I 2 I and I 20 degrees. This was possible because the grains were bounded by curved rather than straight lines. The large grains with more than six sides invariably had boundaries that were concave outwards whereas those for small grains were

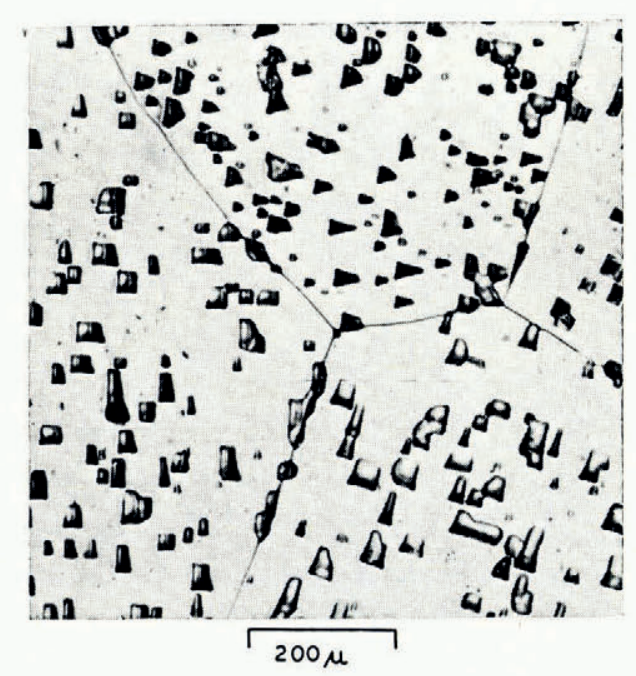

Fig. 7. Grain boundaries forming two tri-crystal joints on a formvar replica of the ice surface. Etch figures are also shown 
convex outwards. It therefore appears that while a wide range of angles was to be found after an equilibrium or near-equilibrium state had been reached, the angles for all grains tended to average 120 degrees, irrespective of their size or shape.

The grain boundary migration usually took place in such a manner that the most acute angle of a tri-crystal joint increased in size, and four grains meeting at a point gave rise to two tri-crystal joints. Curved boundaries tended to move towards their centres of curvature, and hence large grains, mostly having sides that were concave outwards, became still larger. When a boundary apparently moved away from its centre of curvature (or remained stationary despite curvature) it was usually evident that it also had curvature in a plane other than parallel to the ice surface. Instances of such three-dimensional effects were rare.

Certain grains increased in area by as much as one hundred times. This was many times the average increase and could not be accounted for by geometrical effects alone. As a possible alternative, the effect of crystallographic orientations was therefore examined.

\section{Crystallographic Orientations}

Crystallographic orientations of individual grains were determined from the shape of etch pits on their surfaces, using the method described by Aufdermaur and others (1963). This involves making a formvar replica of the ice surface after thermal etching. The basic etch pit possesses the basal plane (OOOI) and prism planes $\{$ Iо İo\}. Angles $\alpha, \beta$ and $\delta$ as shown in Figure 8 for an etch pit of general shape for ice are then measured on the replica. From the three measured angles, angles $\theta$ and $\phi$, which establish the directions of the $c$-axis and $a$-axes, can be derived within a few degrees.

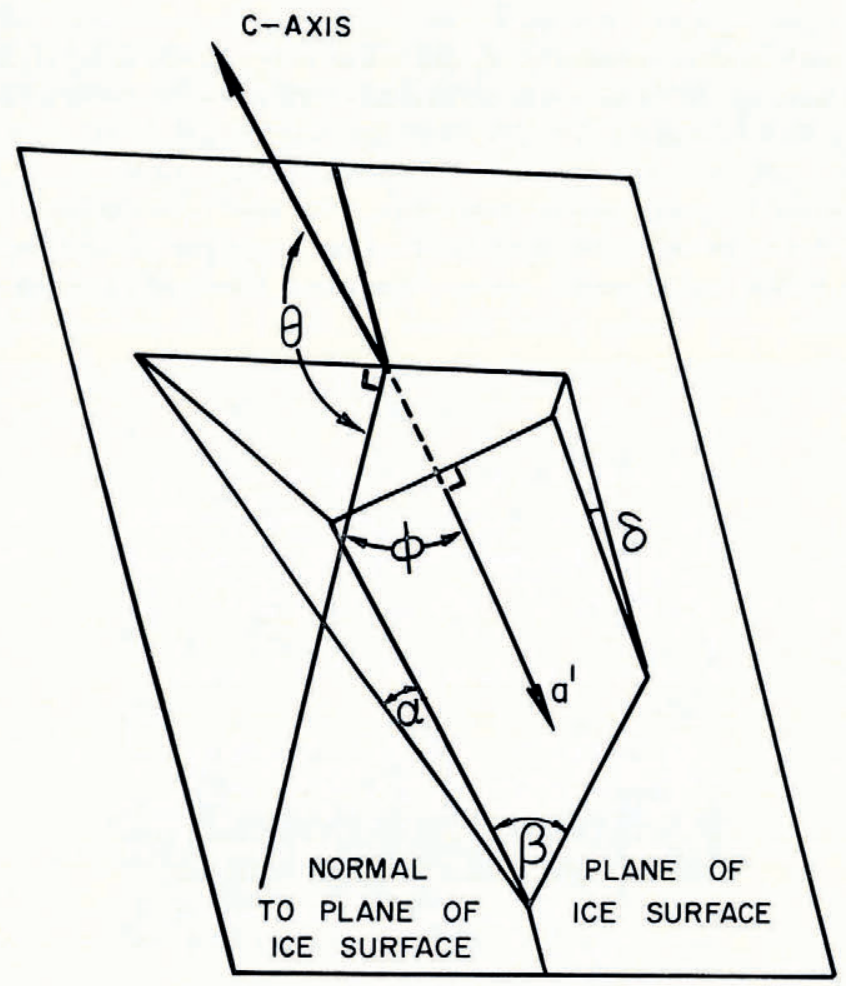

Fig. 8. General shape of an etch pil in ice. Angles $\theta$ and $\phi$ define the directions of the c-axis and a-axes respectively (the a'-axis makes an angle of 30 degrees with an a-axis). $\theta$ and $\phi$ can be determined from measurements of $\alpha, \beta$ and $\delta$ 
A specimen cut from a large hailstone was annealed at $0^{\circ} \mathrm{C}$. for $900 \mathrm{hr}$. After this treatment it comprised 243 grains surrounded on all sides by other grains and 138 grains of each of which at least one side formed part of the perimeter of the specimen. It was found that these surviving grains had a strong tendency towards having their $c$-axes parallel to the plane of the ice surface. The etch pits on nearly half of the grains had shapes basically similar to those in Figure 9 in that $\theta$ was very close to 90 degrees.

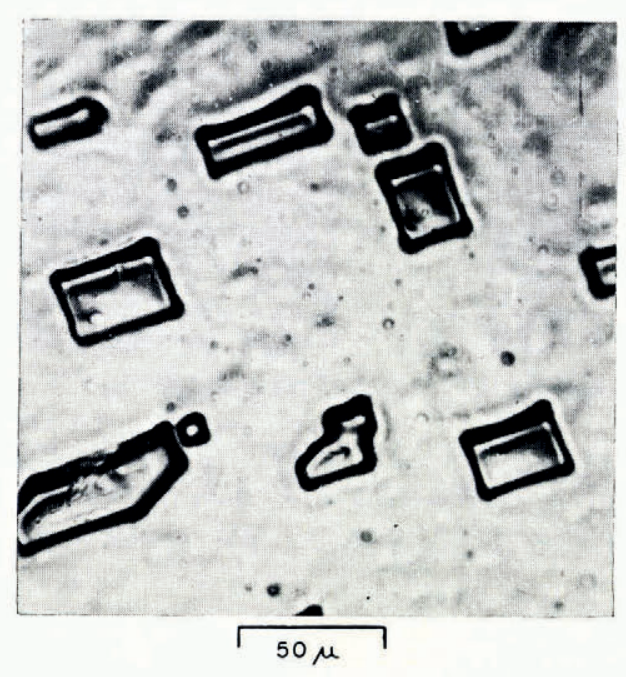

Fig. 9. Etch pits belonging to a grain that has its c-axis parallel to the plane of the ice surface $\left(\theta=90^{\circ},|\phi| \approx 2^{\circ}\right)$

The average value of $\theta$ for the 243 interior grains was 82 degrees. None had a $\theta$-value less than 63 degrees, though a quarter of them had $\theta$ less than 75 degrees. An edge effect on crystallographic orientation was noticed in that a smaller percentage of the ${ }_{1} 3^{8}$ peripheral grains had values of $\theta$ close to 90 degrees as compared with the interior grains.

No preferred orientation of the $a$-axes was found. The average value of $|\phi|$ was 14 degrees, which is close to midway between the possible extreme values of o and 30 degrees. Lastly, the $c$-axes had no preferential orientation other than the above-mentioned tendency for them to lie parallel to the ice surface. There was, for example, no tendency towards radial orientation. It must be mentioned that the crystals in similar hail stones that were not annealed were randomly oriented. Unfortunately it was not possible to determine crystallographic orientations before and after annealing because the ice specimen melted at temperatures below ${ }^{\circ} \mathrm{C}$. after it had been subjected to the replica process.

In view of the finding that crystals with their optic axes in the plane of the ice grew at the expense of others it was surmised that grain growth would be very slow in a thin plate of ice composed of grains with their optic axes all perpendicular to the plate surfaces. This idea was tested experimentally. Specimens of ice were grown in the laboratory by immersing in water a box with flat copper sides $\left(6 \mathrm{~cm}\right.$. square) maintained at $-\mathrm{IO}^{\circ} \mathrm{C}$. by circulating liquid through it. The ice grown in such a manner was made up of many crystals with their $c$-axes approximately normal to the copper surfaces. Thin slices were then cut from this ice giving poly-grain specimens with a high degree of orientation of the $c$-axes perpendicular to the plate surfaces. Annealing of these showed that the average rate of grain area increase was about half of that in sections cut from natural hailstones. 


\section{Conclusion}

The slices used as specimens had a finite thickness and therefore, strictly speaking, the grains could not have experienced growth only in two dimensions, especially not in the earliest stages when they were small. Three-dimensional effects were in fact noted, but the principal effects are thought to have been mainly due to growth in two dimensions. The effect of thickness has not yet been investigated. Thickness cannot be neglected as, for example, it determines the ratio of surface energy to inter-grain energy.

The growth rate was found to be independent of temperature in the $\mathrm{I}^{\circ}$ range immediately below freezing point. It was also concluded that growth rate was practically independent of initial grain size and of the presence of air bubbles.

In the early stages of annealing the rate of increase in average grain diameter was found to be almost exactly inversely proportional to annealing time. After lengthy annealing it became inversely proportional to $t^{5 / 6}$. Therefore, the rate after several hundreds of hours was two orders of magnitude slower than in the early stages during which period the number of grains had decreased by a factor of three or four.

Equilibrium had not been reached in the structure even after $600 \mathrm{hr}$. This might be attributed to one or more of the following: (a) evaporation from the perimeter of the specimen; (b) strains in the ice, perhaps introduced by thermal cycling; (c) residual shape and orientation effects.

It is concluded that both the shape of a grain and its crystallographic orientation relative to its neighbours act jointly in determining the growth process. The one does not dominate the other, otherwise either elongated crystals or grains with randomly oriented $c$-axes would have survived.

\section{Acknowledgement}

Thanks are expressed to Dr. A. E. Carte for his valuable ideas and advice and for his revision of the manuscript.

MS. received Io May 1966

\section{REFERENGES}

Aufdermaur, A. N., and others. 1963. Kristallachsenlagen in Hagelkörnern, von A. N. Aufdermaur, R. List, W. C. Mayes und M. R. de Quervain. Zeitschrift für angewandte Mathematik und Physik, Vol. I4, Fasc. 5, p. $574-89$.

Burke, J. E., and Turnbull, D. 1952. Recrystallization and grain growth. Progress in Metal Physics, [Vol.] 3, p. $220-92$.

Carte, A. E. 196r. Grain growth in ice. Bulletin de l'Observatoire du Puy de Dôme, ${ }^{2}$ e Sér., 1961, No. 3, p. 129-36. Rigsby, G. P. 196o. Crystal orientation in glacier and in experimentally deformed ice. Fournal of Glaciology, Vol. 3, No. 27, p. 589-6o6.

Tamman, G., and Dreyer, K. L. 1929. Die Rekristallisation leicht schmelzender Stoffe und die des Eises. Zeitschrift für Anorganische und Allgemeine Chemie, Bd. 182, Ht. 3, p. 289-313. 